\title{
Determinants Associated with Prolonged Hospital Stays for Patients Aged 65 Years or Older with a Vertebral Compression Fracture in a Rural Hospital in Japan
}

\author{
Yusuke Watanabe, ${ }^{1}$ Shizukiyo Ishikawa, ${ }^{2}$ Hiroyuki Nagata $^{1}$ and Masayuki Kojima ${ }^{3}$ \\ ${ }^{1}$ Department of Internal Medicine, Hitachiomiya Saiseikai Hospital, Hitachiomiya, Ibaraki, Japan \\ ${ }^{2}$ Medical Education Center, Jichi Medical University, Shimotsuke, Tochigi, Japan \\ ${ }^{3}$ Department of Surgery, Hitachiomiya Saiseikai Hospital, Hitachiomiya, Ibaraki, Japan
}

\begin{abstract}
Japan is an aging society, and the incidence of diseases related to aging, such as pneumonia, heart failure, vertebral compression fracture (VCF), is increasing. Prolonged hospital stays are becoming a serious social problem, leading to elevated medical expenses. Thus, shortening the period of hospitalization is important. This study aimed to reveal determinants associated with prolonged hospital stays for patients with VCF. Our institution is the primary hospital in a rural area in the Kanto region of Japan. Altogether, 110 patients with a VCF, aged 65 years or older, including 79 women, were divided into two groups according to the average hospital stay period of 28 days: the long-stay group (mean stay $40.0 \pm 11.6$ days, $\mathrm{n}=39$ ) and the short-stay group (mean stay $20.6 \pm 4.4$ days, $\mathrm{n}=71$ ). Notably, the short-stay group included 55 women. Multivariate logistic regression analyses in male showed no variates significantly associated with prolonged hospitalization. By contrast, multivariate logistic regression analyses in female showed requiring emergency transportation to hospital was significantly associated with prolonged hospitalization [odds ratio $7.69,95 \%$ confidence interval $1.13-52.29, P=0.04$ ]. In conclusion, this study implies that patients with better levels of activities of daily living are able to walk alone sooner and are easily discharged. Furthermore, the patient requiring emergency transportation might be in a poor social living environment, such as living alone. These results may give us a good opportunity to re-consider fundamental problems surrounding the elderly.
\end{abstract}

Keywords: activities of daily living; determinant; elderly patients; long hospital stay; vertebral compression fracture Tohoku J. Exp. Med., 2019 January, 247 (1), 27-34. C 2019 Tohoku University Medical Press

\section{Introduction}

The rate of aging in Japan is currently the highest in the world, and the $\geq 65$-year-old population is projected to account for nearly $40 \%$ of the total population by the year 2050 (Chen et al. 2016). Thus, the prevalence of several diseases, including vertebral compression fracture (VCF), pneumonia, heart failure, and age-related dementia, might increase further (Tsuda 2017; Miyashita and Yamauchi 2018; Shimada et al. 2018). Compared with other developed countries, prolonged hospital stays are considered one of the most serious social problems in Japan (Muramatsu and Liang 1999). A major goal is therefore to shorten the hospitalization period.

Our hospital has the aforementioned problem that our elderly patients with a wide variety of diseases were being hospitalized for long periods. Particularly, elderly patients with VCF were admitted to our hospital and then could not be easily discharged. Several Japanese studies reported that some determinants including the early ambulation program with rehabilitation and the difference of discharge destination were related to the hospital stay period on $\mathrm{VCF}$ (Kumagai et al. 2011; Ogawa et al. 2013). Furthermore, we hypothesized whether prolonged hospital stay periods are related to a social and medical environment around VCF patients living in a rural area and a clinical condition including the ability of walking in addition to these risk factors. The prolonged hospital stay could ensure that elderly patients with VCF could live healthy after discharge. This study aimed to identify the factors that could lead to long hospitalization periods for elderly patients with VCF. The study population thus included elderly patients hospitalized in our facility with VCF that did not require surgery. Our institution is the primary and designated emergency hospital in a rural area in the Kanto region of Japan. In 2015, $31.5 \%$ of the population in this region were $\geq 65$ years of age.

Received October 25, 2018; revised and accepted December 28, 2018. Published online January 17, 2019; doi: 10.1620/tjem.247.27. Correspondence: Yusuke Watanabe, M.D., Department of Internal Medicine, Hitachiomiya Saiseikai Hospital, 3033-3 Tagouchi-cho, Hitachiomiya, Ibaraki 319-2601, Japan.

e-mail: m04100yw@jichi.ac.jp 


\section{Materials and Methods}

This study was approved by the Ethics Committee on Research of Human Subjects at Hitachiomiya Saiseikai Hospital (approval number: 18-03) and was conducted in accordance with the Declaration of Helsinki. Written informed consent was waived because of the study's retrospective design.

Subjects

We evaluated the medical records of all VCF patients admitted to our hospital from January 2016 to December 2017 and collected their data relative to our research. The diagnosis of VCF requires symptoms consistent with a compression fracture and magnetic resonance imaging and/or computed tomography evidence of the fracture.

The inclusion criteria were (1) age $\geq 65$ years; (2) VCF of a thoracic and/or lumbar vertebra; and (3) symptoms of a compression fracture. The exclusion criteria were (1) VCF caused by a highenergy injury, (2) infection, or (3) it was a pathologic fracture; (4) its treatment required surgery; (5) the patient had been hospitalized two or more times; and (6) there was no imaging evidence of a compression fracture. The average hospital stay period in all patients with VCF in this study was $27.5 \pm 12.1$ days, approximately 28 days. We therefore divided the study subjects into those whose hospital stay was $\geq 28$ days (long-stay group) and those whose hospital stayed was $<28$ days (short-stay group). The clinical characteristics were compared between the long- and short-stay groups.

\section{Definitions}

- Hypertension was defined as the patient having had medical treatment for hypertension and/or a history of hypertension before admission.

- Dyslipidemia was defined as a total cholesterol level of $\geq 220 \mathrm{mg} /$ dl and/or low-density lipoprotein cholesterol level $\geq 140 \mathrm{mg} / \mathrm{dl}$ and/or medical treatment for dyslipidemia and/or a history of dyslipidemia.
- Diabetes mellitus was defined as a hemoglobin A1c level of $\geq 6.5 \%$, the National Glycohemoglobin Standardization Program (NGSP) value, and/or medical treatment for diabetes mellitus and/or a history of diabetes mellitus. We also calculated the estimated glomerular filtration rate (eGFR) from the patient's serum creatinine level, age, weight, and sex using the following formulas (Matsuo et al. 2009).

$$
\begin{aligned}
& \mathrm{eGFR}=194 \times \mathrm{Cr}^{-1.094} \times \operatorname{age}^{-0.287}(\text { male }) \\
& \mathrm{eGFR}=194 \times \mathrm{Cr}^{-1.094} \times \mathrm{age}^{-0.287} \times 0.739(\text { female })
\end{aligned}
$$

- Osteoporosis, dementia, and thyroid disease were defined according to the use of the particular medical treatment of each and/or a medical history of the disease. Being an insured person with long-term care insurance was qualified as having a need for long-term care because of the condition in question (Hamada et al. 2018).

\section{Statistical analysis}

Data are expressed as means $\pm \mathrm{SD}$ or as the number and percentage. Categorical variables are presented as numbers (percentage) and were compared by using Pearson's $\chi^{2}$ test or Fisher's exact test. The Kolmogorov-Smirnov test was performed to determine if the continuous variables were normally distributed. Normally distributed continuous variables were compared between the groups by using an unpaired Student's t test. Otherwise, continuous variables were compared by using a Mann-Whitney $U$ test. The multivariate logistic regression model used the variables identified to incur a long hospital stay in the univariate analysis (defined as $\mathrm{P}<0.05$ ) without missing values. All variables were simultaneously adjusted in one step. Furthermore, multivariate logistic regression analysis predicting the long hospitalization period both in the male patient group and in the female patient group used variables that were the risk factors found in the univariate logistic regression analysis in all study population. The odds ratio (OR) and $95 \%$ confidence interval (CI) were calculated. A value of $\mathrm{P}<0.05$ was considered to indicate statistical significance (Wang et al. 2018). All analyses were performed using SPSS 23.0 statistical software/Windows (IBM, Armonk, NY, USA)

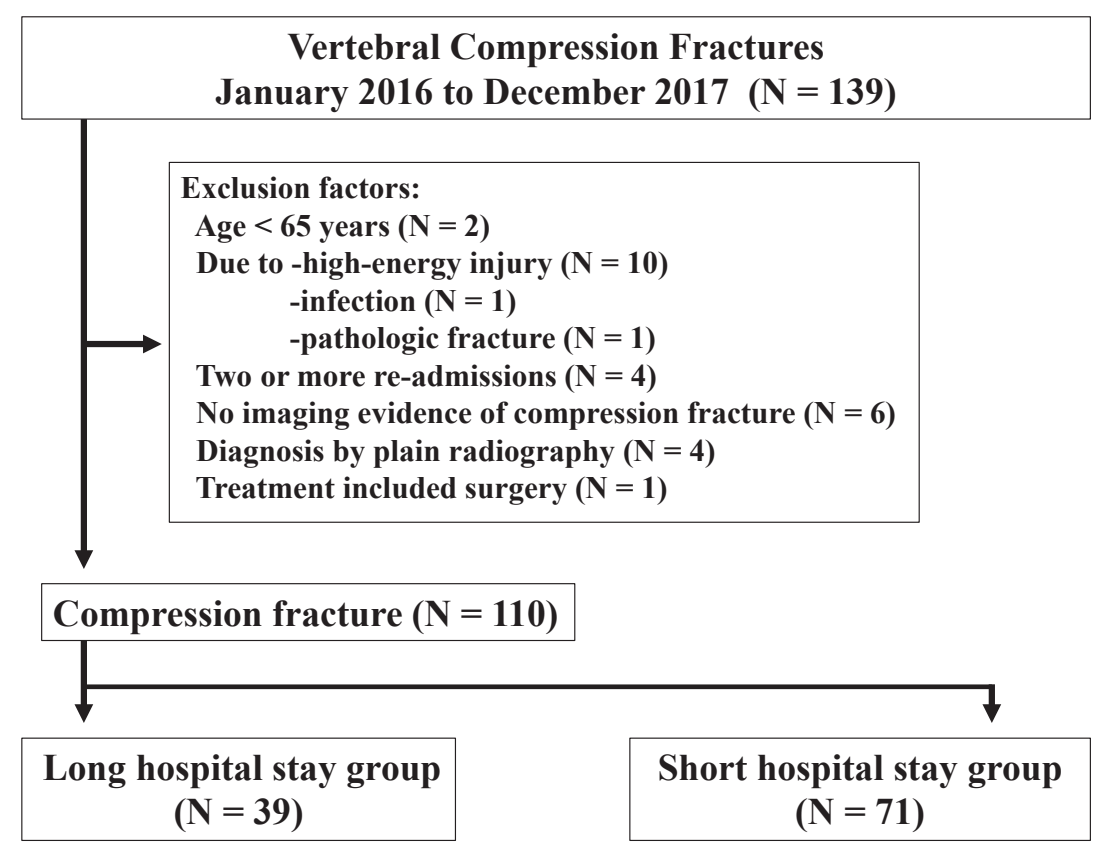

Fig. 1. Flow chart of the study. 


\section{Results}

Among 139 VCF patients admitted to our hospital from January 2016 to December 2017, the final study population included 110 patients (39 in the long-stay group and 71 in the short-stay group) who met the inclusion criteria (Fig. 1).

Table 1 compares patients' characteristic between the long- and short-stay groups. There were 15 men out of 39 VCF patients (38.5\%) in the long-stay group and 16 men out of $71 \mathrm{VCF}$ patients $(22.5 \%)$ in the short-stay group. Mean height was significantly greater in the long-stay group $(150.4 \pm 10.0 \mathrm{~cm})$ than in the short-stay group $(145.5 \pm 8.1$ $\mathrm{cm})(\mathrm{P}=0.01)$. The difference in the mean height may reflect the presence of 55 women in the short-stay group. Patients frequently lived alone in the long-stay group
(43.6\%) than in the short-stay group (23.9\%) $(\mathrm{P}=0.003)$. Levels of activities of daily living (ADL) before onset of the compression fracture were worse in the long-stay group. There were also significantly more long-term care insurance owners in the long-stay group $(51.3 \%)$ than in the shortstay group $(29.6 \%)(\mathrm{P}=0.02)$. The mean serum albumin level was lower in the long-stay group $(3.8 \pm 0.5 \mathrm{mg} / \mathrm{dL})$ than in the short-stay group $(4.0 \pm 0.3 \mathrm{mg} / \mathrm{dL})(\mathrm{P}=0.01)$. The mean white blood cell counts were higher in the longstay group $(7,808 \pm 2,264 / \mu \mathrm{L})$ than in the short-stay group $(6,660 \pm 1,947 / \mu \mathrm{L})(\mathrm{P}=0.003)$.

Table 2 compares the characteristics of VCF and its treatment between the two patient groups. Patients in the long-stay group were significantly more likely to need emergency transportation to the hospital at VCF onset $(20.5 \%)$ than those in the short-stay group $(4.2 \%)(\mathrm{P}=$

Table 1. Patient characteristics of the long and short hospital stay groups.

\begin{tabular}{|c|c|c|c|c|}
\hline Parameters & All $(\mathrm{N}=110)$ & Long hospital stay group $(\mathrm{N}=39)$ & Short hospital stay group $(\mathrm{N}=71)$ & $\mathrm{P}$ \\
\hline \multicolumn{5}{|l|}{ Patient characteristics } \\
\hline Age (years) & $83.0 \pm 6.7(110,100)$ & $83.4 \pm 8.2(39,100)$ & $82.9 \pm 5.9(71,100)$ & 0.74 \\
\hline Male sex & $31(28.2)$ & $15(38.5)$ & $16(22.5)$ & 0.08 \\
\hline Height, cm & $147.3 \pm 9.1(108 / 110,98.2)$ & $150.4 \pm 10.0(38 / 39,97.4)$ & $145.5 \pm 8.1(70 / 71,98.6)$ & 0.01 \\
\hline Body mass index, $\mathrm{kg} / \mathrm{m}^{2}$ & $22.3 \pm 4.0(108 / 110,98.2)$ & $21.8 \pm 4.6(38 / 39,97.4)$ & $22.5 \pm 3.6(70 / 71,98.6)$ & 0.40 \\
\hline Habitual drinking & $15 / 109(13.8)$ & $5 / 39(12.8)$ & $10 / 70(14.3)$ & 0.83 \\
\hline Current and/or Post smoking & $22 / 108(20.4)$ & $10 / 39(25.6)$ & $12 / 69(17.4)$ & 0.31 \\
\hline Living alone & $34(30.9)$ & $17(43.6)$ & $17(23.9)$ & 0.003 \\
\hline ADL before compression fracture & & & & 0.047 \\
\hline Walk by oneself & $86(78.2)$ & $25(64.1)$ & $61(85.9)$ & \\
\hline Walk with self-help tool & $20(18.2)$ & $11(28.2)$ & $9(12.7)$ & \\
\hline Walk along a wall & $1(0.9)$ & $1(2.6)$ & 0 & \\
\hline Walk with human assistance & $3(2.7)$ & $2(5.1)$ & $1(1.4)$ & \\
\hline Long-term care insurance user & $41(37.3)$ & $20(51.3)$ & $21(29.6)$ & 0.02 \\
\hline Long-term care insurance category & & & & 0.09 \\
\hline No usage of long-term care insurance & $69(62.7)$ & $19(48.7)$ & $50(70.4)$ & \\
\hline Requiring support 1 & $4(3.6)$ & $1(2.6)$ & $3(4.2)$ & \\
\hline Requiring support 2 & $9(8.2)$ & $4(10.3)$ & $5(7.0)$ & \\
\hline Requiring long-term care 1 & $11(10.0)$ & $5(12.8)$ & $6(8.5)$ & \\
\hline Requiring long-term care 2 & $10(9.1)$ & $6(15.4)$ & $4(5.6)$ & \\
\hline Requiring long-term care 3 & $5(4.5)$ & $4(10.3)$ & $1(1.4)$ & \\
\hline Requiring long-term care 4 & $2(1.8)$ & 0 & $2(2.8)$ & \\
\hline Requiring long-term care 5 & 0 & 0 & 0 & \\
\hline \multicolumn{5}{|l|}{ Medical history } \\
\hline Prevalence of hypertension & $67(60.9)$ & $26(66.7)$ & $41(57.7)$ & 0.36 \\
\hline Prevalence of dyslipidemia & $37(33.6)$ & $11(28.2)$ & $26(36.6)$ & 0.37 \\
\hline Prevalence of diabetes mellitus & $16(14.5)$ & $5(12.8)$ & $11(15.5)$ & 0.70 \\
\hline Prevalence of osteoporosis & $44(40.0)$ & $16(41.0)$ & $28(39.4)$ & 0.87 \\
\hline Episode of previous vertebral compression fracture & $19(17.3)$ & $9(23.1)$ & $10(14.1)$ & 0.23 \\
\hline Prevalence of atrial fibrillation and/or atrial flutter & $11(10.0)$ & $5(12.8)$ & $6(8.5)$ & 0.34 \\
\hline Prevalence of dementia & $12(10.9)$ & $6(15.4)$ & $6(8.5)$ & 0.21 \\
\hline Prevalence of cerebrovascular disease & $11(10.0)$ & $5(12.8)$ & $6(8.5)$ & 0.34 \\
\hline Cancer-bearing status without early-stage cancer & $20(18.2)$ & $10(25.6)$ & $10(14.1)$ & 0.13 \\
\hline Prevalence of thyroid disease without tumor & $5(4.5)$ & $4(10.3)$ & $1(1.4)$ & 0.05 \\
\hline \multicolumn{5}{|l|}{ Medication on admission } \\
\hline Vitamin Ds & $22(20.0)$ & $9(23.1)$ & $13(18.3)$ & 0.55 \\
\hline Bisphosphonates & $20(18.2)$ & $6(15.4)$ & $14(19.7)$ & 0.57 \\
\hline Diuretics & $15(13.6)$ & $5(12.8)$ & $10(14.1)$ & 0.85 \\
\hline Oral anti-diabetes medicines & $14(12.7)$ & $4(10.3)$ & $10(14.1)$ & 0.40 \\
\hline Oral steroids & $1(0.9)$ & $1(2.6)$ & $0(0.0)$ & 0.36 \\
\hline Proton pump inhibitors & $46(41.9)$ & $16(41.0)$ & $30(42.3)$ & 0.90 \\
\hline Warfarin & $2(1.8)$ & $1(2.6)$ & $1(1.4)$ & 0.59 \\
\hline \multicolumn{5}{|l|}{ Laboratory data at admission } \\
\hline Serum albumin, $\mathrm{g} / \mathrm{dL}$ & $3.9 \pm 0.4(109 / 110,99.1)$ & $3.8 \pm 0.5(39 / 39,100)$ & $4.0 \pm 0.3(70 / 71,98.6)$ & 0.01 \\
\hline Lactate dehydrogenase, U/L & $246 \pm 65(109 / 110,99.1)$ & $261 \pm 83(39 / 39,100)$ & $237 \pm 51(70 / 71,98.6)$ & 0.18 \\
\hline Serum sodium, $\mathrm{mEq} / \mathrm{L}$ & $139.4 \pm 3.9(109 / 110,99.1)$ & $137.3 \pm 4.4(39 / 39,100)$ & $139.8 \pm 3.6(70 / 71,98.6)$ & 0.17 \\
\hline Serum creatinine, $\mathrm{mg} / \mathrm{dL}$ & $0.72 \pm 0.23(109 / 110,99.1)$ & $0.73 \pm 0.23(39 / 39,100)$ & $0.72 \pm 0.23(70 / 71,98.6)$ & 0.65 \\
\hline Estimated glomerular filtration rate, $\mathrm{mL} / \mathrm{min} / 1.73 \mathrm{~m}^{2}$ & $69.5 \pm 22.7(109 / 110,99.1)$ & $71.9 \pm 26.7(39 / 39,100)$ & $68.3 \pm 20.3(70 / 71,98.6)$ & 0.70 \\
\hline White blood cells, $/ \mu \mathrm{L}$ & $7,071 \pm 2,129(109 / 110,99.1)$ & $7,808 \pm 2,264(39 / 39,100)$ & $6,660 \pm 1,947(70 / 71,98.6)$ & 0.003 \\
\hline
\end{tabular}

Results are expressed as the number (\%) or the mean \pm SD (number/total number, \%).

Categorical variables were compared with Pearson's $\chi^{2}$ test or Fisher's exact test and presented as the number (\%). KolmogorovSmirnov test was performed to determine if the continuous variables were normally distributed. Continuous variables were compared using an unpaired Student's $t$ test or a Mann-Whitney U-test and are presented as the mean \pm significant deviation. $\mathrm{P}<0.05$ is considered to indicate statistical significance. 
Table 2. Characteristics of compression fracture and its treatment between the long and short hospital stay groups.

\begin{tabular}{|c|c|c|c|c|}
\hline Compression fracture data & All $(\mathrm{N}=110)$ & Long hospital stay group $(\mathrm{N}=39)$ & Short hospital stay group $(\mathrm{N}=71)$ & $\mathrm{P}$ \\
\hline \multicolumn{5}{|l|}{ Characteristics } \\
\hline \multicolumn{4}{|l|}{ Causes of vertebral compression fracture } & \multirow[t]{5}{*}{0.12} \\
\hline Turnover & $47(42.7)$ & $22(56.4)$ & $25(35.2)$ & \\
\hline Minor trauma except turnover & $18(16.4)$ & $3(7.7)$ & $15(21.1)$ & \\
\hline Lifting heavy objects & $15(13.6)$ & $5(12.8)$ & $10(14.1)$ & \\
\hline Fracture (not obvious) & $30(27.3)$ & $9(23.1)$ & $21(29.6)$ & \\
\hline Emergency transportation to hospital & $11(10.0)$ & $8(20.5)$ & $3(4.2)$ & 0.02 \\
\hline \multicolumn{4}{|c|}{ Details of detection device for compression fracture } & \multirow[t]{3}{*}{0.59} \\
\hline Magnetic resonance imaging & $108(98.2)$ & $38(97.4)$ & $70(98.6)$ & \\
\hline Computed tomography & $2(1.8)$ & $1(2.6)$ & $1(1.4)$ & \\
\hline Multiple compression fracture on image & $22(20.0)$ & $9(23.1)$ & $13(18.3)$ & 0.55 \\
\hline Old compression fracture on image & $63(57.3)$ & $26(66.7)$ & $37(52.1)$ & 0.14 \\
\hline \multicolumn{5}{|l|}{ Treatment during hospitalization } \\
\hline Elcatonin & $57(51.8)$ & $22(56.4)$ & $35(49.3)$ & 0.48 \\
\hline Bisphosphonates during hospital stay & $22(20.0)$ & $8(20.5)$ & $14(19.7)$ & 0.92 \\
\hline Creation of new corset during hospital stay & $84(76.4)$ & $32(82.1)$ & $52(73.2)$ & 0.30 \\
\hline Rehabilitation & $110(100.0)$ & $39(100.0)$ & $71(100.0)$ & N/A \\
\hline Rehabilitation started on admission, days & $3.75 \pm 2.9(110,100)$ & $4.3 \pm 3.5(39,100)$ & $3.5 \pm 2.4(71,100)$ & 0.17 \\
\hline
\end{tabular}

Results are expressed as the number (\%).

Categorical variables were compared with a Pearson's $\chi^{2}$ test or Fisher's exact test and presented as number (percentage). KolmogorovSmirnov test was performed to determine if the continuous variables were normally distributed. Continuous variables were compared using an unpaired Student's $t$ test or a Mann-Whitney $U$ test and are presented as mean \pm SD.

$\mathrm{P}<0.05$ is considered to indicate statistical significance.

Table 3. Clinical outcomes in the long and the short hospital stay groups.

\begin{tabular}{lccc}
\hline \multicolumn{1}{c}{ Outcomes } & All $(\mathrm{N}=110)$ & Long hospital stay group $(\mathrm{N}=39)$ & Short hospital stay group (N=71) \\
\hline Hospitalization period, days & $27.5 \pm 12.1(110,100)$ & $40.0 \pm 11.6(39,100)$ & $20.6 \pm 4.4(71,100)$ \\
Discharge destination & & & $<0.001$ \\
$\quad$ Discharge to home & $102(92.7)$ & $32(82.1)$ & $70(98.6)$ \\
$\quad$ Discharge to nursing home & $6(5.5)$ & $5(12.8)$ & $1(1.4)$ \\
$\quad$ Transfer to other hospital & $2(1.8)$ & $2(5.1)$ & 0 \\
Delirium during hospitalization & $11(10.0)$ & $5(12.8)$ & $6(8.5)$ \\
ADL at discharge & $71(64.5)$ & $18(46.2)$ & $53(74.6)$ \\
$\quad$ Walk by oneself & $31(28.2)$ & $16(41.0)$ & $15(21.1)$ \\
Walk with self-help tool & $3(2.7)$ & $1(2.6)$ & $2(2.8)$ \\
Walk along a wall & $5(4.5)$ & $410.3)$ & $1(1.4)$ \\
$\quad$ Walk with human assistance & $19(17.3)$ & $9(23.1)$ & 0.34 \\
Deterioration of levels of ADL & $14.3 \pm 7.5(71,64.5)$ & $21.7 \pm 6.8(18,46.2)$ & $10(14.1)$ \\
Period for acquiring ability to walk by oneself, days & & 0.01 \\
\hline
\end{tabular}

Results are expressed as the number (\%), or the mean \pm SD (number, \%).

Categorical variables were compared with Pearson's $\chi^{2}$ test or Fisher's exact test and are presented as the number (percentage). Kolmogorov-Smirnov test was performed to determine if the continuous variables were normally distributed. Continuous variables were compared using an unpaired Student's t test or a Mann-Whitney U test and are presented as mean \pm SD.

$\mathrm{P}<0.05$ is considered to indicate statistical significance.

ADL, activities of daily living.

$0.02)$.

Table 3 shows the clinical outcomes for the two groups. The mean hospitalization period for all patients was $27.5 \pm 12.1$ days. Patients in the long-stay group were more likely to be discharged to somewhere other than their homes than those in the short-stay group. Period for acquiring an ability to walk by oneself was significantly longer in the long-stay group $(21.7 \pm 6.8$ days $)$ than in the short-stay group $(11.8 \pm 6.0$ days $)(\mathrm{P}<0.001)$. The prevalence of deterioration of levels of ADL was similar in the two groups, and there was no one whose levels of ADL were improved during hospitalization compared with ADL before admission.

Table 4 shows the univariate and multivariate logistic regression analyses to identify factors that predict prolonged hospitalization stays. The univariate logistic regres- sion analysis showed that the following factors were significantly associated with a long hospital stay: the patient's height, serum albumin level, and white blood cell count; living alone; walking by oneself before the compression fracture; owning long-term care insurance; requiring emergency transportation to the hospital; ability of walking by oneself at discharge; and discharged to home. The multivariate logistic regression analysis model indicated that the living alone and the ability of walking by oneself at discharge were significantly associated with prolonged hospitalization, including variables identified in the univariate analysis that would incur a long hospital stay.

We then analyzed the variables found in the univariate logistic regression analysis of the all study population in the male patient group $(\mathrm{N}=31)$ and in the female patient group $(\mathrm{N}=79)$, respectively. The male group was also divided 
Table 4. Univariate and multivariate logistic regression analyses predicting long hospitalization periods.

\begin{tabular}{|c|c|c|c|c|c|c|}
\hline \multirow[b]{2}{*}{ Factors } & \multicolumn{3}{|c|}{ Univariate analysis } & \multicolumn{3}{|c|}{ Multivariate analysis } \\
\hline & OR & $95 \% \mathrm{CI}$ & $\mathrm{P}$ & OR & $95 \% \mathrm{CI}$ & $\mathrm{P}$ \\
\hline \multicolumn{7}{|l|}{ Continuous variables } \\
\hline Age (per 1 year old) & 1.01 & $0.95-1.07$ & 0.71 & & & \\
\hline Height (per $10 \mathrm{~cm}$ ) & 1.70 & $1.09-2.64$ & 0.02 & & & \\
\hline Serum albumin (per $1 \mathrm{~g} / \mathrm{dL})$ & 0.19 & $0.06-0.57$ & 0.003 & & & \\
\hline White blood cell count (per $1,000 / \mu \mathrm{L}$ ) & 1.31 & $1.07-1.59$ & 0.01 & & & \\
\hline Period for acquiring ability to walk by oneself & 1.29 & $1.13-1.48$ & $<0.001$ & & & \\
\hline \multicolumn{7}{|l|}{ Categorical variables } \\
\hline Male sex & 2.15 & $0.92-5.04$ & 0.08 & & & \\
\hline Living alone & 2.46 & $1.07-5.66$ & 0.04 & 2.68 & $1.01-7.12$ & 0.048 \\
\hline Walking by oneself before compression fracture & 0.29 & $0.12-0.75$ & 0.01 & & & \\
\hline Long-term care insurance usage & 2.51 & $1.12-5.63$ & 0.03 & 1.36 & $0.53-3.48$ & 0.53 \\
\hline Osteoporosis & 1.07 & $0.48-2.39$ & 0.87 & & & \\
\hline Episode of previous compression fracture & 1.83 & $0.67-4.98$ & 0.24 & & & \\
\hline Emergency transportation to emergency department & 5.85 & $1.45-23.56$ & 0.01 & 3.28 & $0.69-15.62$ & 0.14 \\
\hline Multiple compression fractures on imaging & 1.34 & $0.51-3.49$ & 0.55 & & & \\
\hline Creation of new corset during hospital stay & 1.67 & $0.63-4.42$ & 0.30 & & & \\
\hline Walking by oneself at discharge & 0.29 & $0.13-0.67$ & 0.003 & 0.32 & $0.12-0.83$ & 0.02 \\
\hline Discharge to home & 0.07 & $0.01-0.55$ & 0.01 & 0.13 & $0.01-1.21$ & 0.07 \\
\hline
\end{tabular}

Multivariate logistic regression model used variables found in the univariate analysis to incur a long hospital stay (significance defined as $\mathrm{P}<0.05$ ) without missing values. All variables were simultaneously adjusted in one step. Significant variables in the model were living alone, long-term care insurance usage, requiring emergency transportation to hospital, walking by oneself at discharge, and discharge to home.

$\mathrm{P}<0.05$ is considered to indicate statistical significance.

OR, odds ratio; CI, confidence interval.

into the long-stay group $(\mathrm{N}=15$, hospitalization period $42.2 \pm 14.9$ days $)$ and the short-stay group $(\mathrm{N}=16$, hospitalization period $20.3 \pm 4.6$ days) according to this study definition. The female group was also divided into the long-stay group $(\mathrm{N}=24$, hospitalization period $38.7 \pm 9.1$ days) and the short-stay group $(\mathrm{N}=55$, hospitalization period $20.7 \pm 4.4$ days) according to this study definition. Table 5 showed univariate and multivariate logistic regression model both in the male patient group and the female patient group. Multivariate logistic regression model in the male patient group showed no significant variable associated with the prolonged hospital stay. By contrast, multivariate logistic regression model in the female patient group showed that the requiring emergency transportation to emergency department (ED) was significantly associated with prolonged hospitalization, and the living alone as well as the ability of walking by oneself at discharge trended to prolong hospitalization periods.

\section{Discussion}

VCF is one of the leading causes of hospitalization among elderly people. This is especially true in Japan, which is becoming a super-aging society (Arai et al. 2015). The mean hospital stay in Japan is considerably longer than in other developed countries and is becoming a serious social problem (Akiyama 2001). Prolonged hospitalization vastly increases medical expenses, and the problem must be considered and solved. Several studies that examined determinants for long hospital stays to identify ways to shorten the hospitalization period have been reported (Kuroda et al. 1992; Langhorne and Baylan 2017). However, effects of the living alone and ability to walk at discharge toward the prolonged hospital stay of VCF patients shown in this study were not mentioned in previous studies. Moreover, few focused on factors associated with long hospitalization periods in rural areas with limited medical resources compared with those in urban areas (Habibov 2010).

In the present study, we showed that patients who lived alone stayed in hospital longer than patients who lived with other family members. Indeed, several studies have shown that living alone was a risk factor for mortality, longer hospital stays following surgery, numerous readmissions, and more expensive medical costs for the elderly (Tabue Teguo et al. 2016; Turner et al. 2016). Unfortunately, the living alone is thought to be increasing in Japan. The problems of the increased number of older persons living alone, their longer hospitalization times, and the increased medical costs have not only been addressed by health care providers but are a concern of the general population benefiting from the present medical system in Japan. Also, older patients living alone might experience anxiety about the possibility of re-admission due to symptom recurrence after discharge (Andreasen et al. 2015). It is thus a challenging issue to try to reassure these patients, even before their admission, that they could be discharged without anxiety. Hence, we should work toward reducing their anxiety from beginning on the day of admission perhaps by coordinating their living environment with a care service system for the elderly, such as home nursing (Nordin et al. 2015).

This study showed that patients who could walk by themselves at discharge stayed in hospital a significantly shorter time than patients with lower ADL. Some studies reported that lower levels of ADL of elderly patients were a risk factor for longer hospital stays and depression (Zanocchi et al. 2002; Unsar et al. 2015). It has been 
Table 5. Univariate and multivariate logistic regression analyses in the female patient group and the male patient group predicting long hospitalization periods.

\begin{tabular}{|c|c|c|c|c|c|c|}
\hline \multicolumn{7}{|l|}{ Male patient group } \\
\hline \multirow[b]{2}{*}{ Factors } & \multicolumn{3}{|c|}{ Univariate analysis } & \multicolumn{3}{|c|}{ Multivariate analysis } \\
\hline & OR & $95 \% \mathrm{CI}$ & $\mathrm{P}$ & OR & $95 \% \mathrm{CI}$ & $\mathrm{P}$ \\
\hline \multicolumn{7}{|l|}{ Continuous variables } \\
\hline Age (per 1 year old) & 1.01 & $0.90-1.13$ & 0.88 & & & \\
\hline Height (per $1 \mathrm{~cm})$ & 1.01 & $0.97-1.21$ & 0.16 & & & \\
\hline Serum albumin (per $1 \mathrm{~g} / \mathrm{dL})$ & 0.12 & $0.02-0.84$ & 0.03 & & & \\
\hline Lactate dehydrogenase （per $1 \mathrm{U} / \mathrm{L} ）$ & 0.99 & $0.98-1.01$ & 0.24 & & & \\
\hline White blood cell count (per $1,000 / \mu \mathrm{L}$ ) & 0.69 & $0.39-1.24$ & 0.21 & & & \\
\hline Period for acquiring ability to walk by oneself & 1.34 & $1.01-1.77$ & 0.04 & & & \\
\hline \multicolumn{7}{|l|}{ Categorical variables } \\
\hline Living alone & 1.10 & $0.24-4.96$ & 0.90 & 1.17 & $0.2-6.54$ & 0.86 \\
\hline Walking by oneself before compression fracture & 0.13 & $0.01-1.32$ & 0.09 & & & \\
\hline Walking by oneself at discharge & 0.23 & $0.05-1.03$ & 0.05 & 0.28 & $0.06-1.38$ & 0.12 \\
\hline Long-term care insurance usage & 3.43 & $0.75-15.67$ & 0.11 & 2.84 & $0.49-16.51$ & 0.24 \\
\hline Osteoporosis & 1.10 & $0.24-4.96$ & 0.90 & & & \\
\hline Episode of previous compression fracture & 1.55 & $0.45-5.33$ & 0.49 & & & \\
\hline Cancer-bearing status without early-stage cancer & 8.00 & $1.33-48.18$ & 0.02 & & & \\
\hline Emergency transportation to emergency department & 1.07 & $0.06-18.82$ & 0.96 & 0.51 & $0.02-12.80$ & 0.68 \\
\hline Multiple compression fractures on imaging & 2.55 & $0.39-16.55$ & 0.33 & & & \\
\hline Creation of new corset during hospital stay & 6.36 & $0.65-62.69$ & 0.11 & & & \\
\hline Discharge to home & N/A & N/A & N/A & N/A & N/A & N/A \\
\hline \multicolumn{7}{|l|}{ Female patient group } \\
\hline & \multicolumn{3}{|c|}{ Univariate analysis } & \multicolumn{3}{|c|}{ Multivariate analysis } \\
\hline Factors & OR & $95 \% \mathrm{CI}$ & $\mathrm{P}$ & OR & $95 \% \mathrm{CI}$ & $\mathrm{P}$ \\
\hline \multicolumn{7}{|l|}{ Continuous variables } \\
\hline Age (per 1 year old) & 1.01 & $0.94-1.09$ & 0.78 & & & \\
\hline Height (per $1 \mathrm{~cm}$ ) & 1.06 & $0.99-1.14$ & 0.10 & & & \\
\hline Lactate dehydrogenase (per $1 \mathrm{U} / \mathrm{L}$ ) & 1.01 & $1.00-1.02$ & 0.02 & & & \\
\hline White blood cell count (per $1,000 / \mu \mathrm{L})$ & 1.29 & $1.02-1.63$ & 0.03 & & & \\
\hline Period for acquiring ability to walk by oneself & 1.28 & $1.10-1.48$ & 0.001 & & & \\
\hline \multicolumn{7}{|l|}{ Categorical variables } \\
\hline Living alone & 3.58 & $1.29-9.98$ & 0.02 & 3.21 & $0.94-10.98$ & 0.06 \\
\hline Walking by oneself before compression fracture & 0.37 & $0.13-1.08$ & 0.07 & & & \\
\hline Walking by oneself at discharge & 0.37 & $0.13-1.01$ & 0.05 & 0.31 & $0.09-1.06$ & 0.06 \\
\hline Long-term care insurance usage & 2.24 & $0.84-5.98$ & 0.11 & 1.42 & $0.43-4.71$ & 0.57 \\
\hline Osteoporosis & 1.18 & $0.45-3.09$ & 0.74 & & & \\
\hline Episode of previous compression fracture & 1.55 & $0.45-5.33$ & 0.49 & & & \\
\hline Thyroid disease without tumor & 10.8 & $1.14-102.53$ & 0.04 & & & \\
\hline Emergency transportation to emergent department & 10.91 & $2.07-57.60$ & 0.005 & 7.69 & $1.13-52.29$ & 0.04 \\
\hline Multiple compression fractures on imaging & 1.05 & $0.32-3.45$ & 0.93 & & & \\
\hline Turnover as cause of vertebral compression fracture & 3.16 & $1.17-8.55$ & 0.02 & & & \\
\hline Creation of new corset during hospital stay & 1.20 & $0.34-3.09$ & 0.97 & & & \\
\hline Discharge to home & 0.20 & $0.02-2.36$ & 0.20 & 0.68 & $0.04-13.24$ & 0.80 \\
\hline \multicolumn{7}{|c|}{$\begin{array}{l}\text { Multivariate logistic regression model used variables found in the univariate analysis of all study population to incur a long hospital stay } \\
\text { (significance defined as } \mathrm{P}<0.05 \text { ) without missing values. All variables were simultaneously adjusted in one step. Significant variables } \\
\text { in the model were living alone, long-term care insurance usage, requiring emergency transportation to hospital, walking by oneself at } \\
\text { discharge, and discharge to home. Variable of discharge to home was not analyzed in multivariate logistic regression model of the male } \\
\text { patient group, because all patients in the short group could discharge to their own home. } \\
\mathrm{P}<0.05 \text { is considered to indicate statistical significance. } \\
\text { OR, odds ratio; } \mathrm{CI} \text {, confidence interval. }\end{array}$} \\
\hline
\end{tabular}

shown that aggressive support of elderly patients during hospitalization to maintain their ADL enabled them to maintain post-hospitalization mobility (Brown et al. 2016). We should make efforts to help patients with VCF to maintain their ADL; thus, their anxiety remains at a low level. Moreover, we should not forget that these patients who are living alone and/or with lower levels of ADL may need more support than those living with family and/or with higher levels of ADL. We therefore should hold a conference with several members including a caregiver to support a patient after discharge from early phase of hospital stay (Ulin et al. 2016). Furthermore, a study showed that longstay nursing home residents with better levels of ADL before hospitalization had a better prognosis after hospitalization (Kruse et al. 2013). Univariate regression analysis in this study showed that the ability to walk alone before onset of VCF and at discharge were negatively associated with prolonged hospitalization. Moreover, this study showed that patients with VCF who could not walk alone before onset of VCF was not able to walk alone during hospitalization, and were hospitalized for longer time. It is therefore important that we should support the elderly patients to sustain their levels of ADL before hospitalization.

The present study showed that the patients with VCF in the female group requiring an emergency transportation 
to ED was significantly associated with the prolonged hospital stay. This study also showed that the patients requiring an emergency transportation to ED $(66.7 \%)$ were likely to live alone compared with those who did not need emergency transportation to ED $(25.7 \%)(\mathrm{P}=0.02)$. It appears that the patients who needed emergency transportation were in relatively poor social living environment.

This study has some limitations: first, because the study was based on a single-center, retrospective, observational design, there is a risk of selection bias. Second, because our study population was relatively small, our statistical analysis has an inherent risk of a $\beta$ error (Brogan et al. 1994). This study lacked some background data on the patients, including bone mineral density, young adult mean level of bone mineral density, and degree of pain related to the VCF. Finally, the study was conducted in one limited rural area, therefore, further studies in other setting including other rural areas must be necessary to conclude our findings.

In conclusion, the conditions of living alone and the inability of walking alone after discharge were determinants significantly associated with prolonged hospitalization. This study might imply that patients with better levels of ADL are earlier able to walk alone and are easily discharged. Furthermore, the patient requiring emergency transportation to ED might be in a poor social living environment. However, this study had several limitations, one of which was its relatively small study population. Future research is therefore necessary to elucidate the determinants of prolonged hospitalizations for elderly patients with VCF.

\section{Acknowledgments}

We thank Nancy Schatken, B.S., M.T. (ASCP), from Edanz Group (www.edanzediting.com/ac), for editing a draft of this manuscript.

\section{Conflict of Interest}

The authors declare no conflict of interest.

\section{References}

Akiyama, H. (2001) Health care reform in Japan. World Hosp. Health Serv., 37, 3-6, 33, 35.

Andreasen, J., Lund, H., Aadahl, M. \& Sorensen, E.E. (2015) The experience of daily life of acutely admitted frail elderly patients one week after discharge from the hospital. Int. J. Qual. Stud. Health Well-being, 10, 27370.

Arai, H., Ouchi, Y., Toba, K., Endo, T., Shimokado, K., Tsubota, K., Matsuo, S., Mori, H., Yumura, W., Yokode, M., Rakugi, H. \& Ohshima, S. (2015) Japan as the front-runner of super-aged societies: perspectives from medicine and medical care in Japan. Geriatr. Gerontol. Int., 15, 673-687.

Brogan, G.X. Jr., Friedman, S., McCuskey, C., Cooling, D.S., Berrutti, L., Thode, H.C. Jr. \& Bock, J.L. (1994) Evaluation of a new rapid quantitative immunoassay for serum myoglobin versus CK-MB for ruling out acute myocardial infarction in the emergency department. Ann. Emerg. Med., 24, 665-671.

Brown, C.J., Foley, K.T., Lowman, J.D. Jr., MacLennan, P.A., Razjouyan, J., Najafi, B., Locher, J. \& Allman, R.M. (2016) Comparison of posthospitalization function and community mobility in hospital mobility program and usual care patients: a randomized clinical trial. JAMA Intern. Med., 176, 921-927.

Chen, B.K., Jalal, H., Hashimoto, H., Suen, S.C., Eggleston, K., Hurley, M., Schoemaker, L. \& Bhattacharya, J. (2016) Forecasting trends in disability in a super-aging society: adapting the future elderly model to Japan. J. Econ. Ageing, 8, 42-51.

Habibov, N. (2010) Hospitalization in Tajikistan: determinants of admission, length of stay, and out-of-pocket expenditures. Results of a national survey. Int. J. Health Plann. Manage., 25, 251-269.

Hamada, S., Takahashi, H., Sakata, N., Jeon, B., Mori, T., Iijima, K., Yoshie, S., Ishizaki, T. \& Tamiya, N. (2018) Household income relationship with health services utilization and healthcare expenditures in people aged 75 years or older in Japan: a population-based study using medical and long-term care insurance claims data. J. Epidemiol., doi: 10.2188/jea. JE20180055.

Kruse, R.L., Petroski, G.F., Mehr, D.R., Banaszak-Holl, J. \& Intrator, O. (2013) Activity of daily living trajectories surrounding acute hospitalization of long-stay nursing home residents. J. Am. Geriatr. Soc., 61, 1909-1918.

Kumagai, G., Aburakawa, S., Satoh, H., Ogawa, T. \& Kudoh, Y. (2011) Outcome of life environment for patients with spinal compression fracture. Tohoku J. Orthop. Traumatol., 55, 19-22 (in Japanese).

Kuroda, K., Tatara, K., Takatorige, T., Zhao, L. \& Shinsho, F. (1992) Factors related to long-term stay in hospital by elderly people in a Japanese city. Age Ageing, 21, 321-327.

Langhorne, P. \& Baylan, S. (2017) Early supported discharge services for people with acute stroke. Cochrane Database Syst. Rev., 7, Cd000443.

Matsuo, S., Imai, E., Horio, M., Yasuda, Y., Tomita, K., Nitta, K., Yamagata, K., Tomino, Y., Yokoyama, H. \& Hishida, A. (2009) Revised equations for estimated GFR from serum creatinine in Japan. Am. J. Kidney Dis., 53, 982-992.

Miyashita, N. \& Yamauchi, Y. (2018) Bacterial pneumonia in elderly Japanese populations. Jpn. Clin. Med., 9, 1179670717751433.

Muramatsu, N. \& Liang, J. (1999) Hospital length of stay in the United States and Japan: a case study of myocardial infarction patients. Int. J. Health Serv., 29, 189-209.

Nordin, A., Sunnerhagen, K.S. \& Axelsson, A.B. (2015) Patients' expectations of coming home with very early supported discharge and home rehabilitation after stroke: an interview study. BMC Neurol., 15, 235.

Ogawa, T., Morimoto, Y., Sarukawa, J., Suzuki, D., Nishikino, S. \& Yamazaki, K. (2013) Clinical pathway for vertebral compression fracture in patient with ospeoporosis. Cent. Jpn. J. Orthop. Traumat., 56, 687-688 (in Japanese).

Shimada, H., Doi, T., Lee, S., Makizako, H., Chen, L.K. \& Arai, H. (2018) Cognitive frailty predicts incident dementia among community-dwelling older people. J. Clin. Med., 7, 250.

Tabue Teguo, M., Simo-Tabue, N., Stoykova, R., Meillon, C., Cogne, M., Amieva, H. \& Dartigues, J.F. (2016) Feelings of loneliness and living alone as predictors of mortality in the elderly: the PAQUID study. Psychosom. Med., 78, 904-909.

Tsuda, T. (2017) Epidemiology of fragility fractures and fall prevention in the elderly: a systematic review of the literature. Curr. Orthop. Pract., 28, 580-585.

Turner, A.J., Nikolova, S. \& Sutton, M. (2016) The effect of living alone on the costs and benefits of surgery amongst older people. Soc. Sci. Med., 150, 95-103.

Ulin, K., Olsson, L.E., Wolf, A. \& Ekman, I. (2016) Personcentred care: an approach that improves the discharge process. Eur. J. Cardiovasc. Nurs., 15, e19-26.

Unsar, S., Dindar, I. \& Kurt, S. (2015) Activities of daily living, quality of life, social support and depression levels of elderly individuals in Turkish society. J. Pak. Med. Assoc., 65, 642-646.

Wang, L., Wang, F., Liu, J., Zhang, Q. \& Lei, P. (2018) Inverse 
relationship between baseline serum albumin levels and risk of mild cognitive impairment in elderly: a seven-year retrospective cohort study. Tohoku J. Exp. Med., 246, 51-57.

Zanocchi, M., Maero, B., Maina, P., Ponzetto, M., Francisetti, F.,
Giona, E., Nicola, E., Neirotti, M. \& Fabris, F. (2002) Factors predicting a prolonged hospital stay in elderly patients. Minerva Med., 93, 135-143. 